\title{
CYCLITOLS IN MATURING GRAINS OF WHEAT, TRITICALE AND BARLEY
}

\author{
LESŁAW B. LAHUTA*, JOANNA GOSZCZYŃSKA \\ Department of Plant Physiology and Biotechnology, \\ University of Warmia and Mazury in Olsztyn \\ Oczapowskiego 1A/103, 10-719 Olsztyn, Poland \\ *e-mail: lahuta@uwm.edu.pl
}

(Received: January 20, 2010. Accepted: May 14, 2010)

\begin{abstract}
In the present study, the feeding of stem-flag leaf-ear explants of wheat, triticale and barley with D-chiro-inositol and D-pinitol was used for modification of the composition of soluble carbohydrates in grains without genetic transformation of plants. Maturing grains indicated ability to uptake exogenously applied cyclitols, not occurring naturally in cereal plants, and synthesized their $\alpha$-D-galactosides. The pattern of changes in soluble carbohydrates during grain maturation and germination was not disturbed by the uptake and accumulation of cyclitols. Both, D-chiro-inositol and D-pinitol as well as their $\alpha$-D-galactosides can be an additional pool of soluble carbohydrates accumulated by maturing grains, without decreasing seeds viability. This is the first report indicating the possibility of introduction of cyclitols with potentially human health benefits properties into cereal grains.
\end{abstract}

KEY WORDS: D-chiro-inositol, D-pinitol, carbohydrate, raffinose, kestose, grains.

\section{INTRODUCTION}

Soluble carbohydrates like monosaccharides and sucrose are primary products of photosynthesis and play an essential role in metabolism, development and maturation of sink organs. In maturing seeds, by acting as signal molecules soluble carbohydrates can also regulate embryo development. At the late stages of maturation, beside sucrose seeds also accumulate oligosaccharides $-\alpha$-D-galactosides of sucrose - raffinose family oligosaccharides (RFOs) or different fructosyl derivatives of sucrose (fructan series, in cereal grains). RFOs are ubiquitous in legumes seeds (Obendorf 1997), but in cereal grains raffinose dominates among RFOs, whereas stachyose is present at a very low level (Henry and Saini 1989). Rye grains contain greater concentrations of high molecular weight fructan whereas wheat and barley accumulate higher concentrations of fructan tri- and tetrasaccharides (Henry and Saini 1989). RFOs may function as "compatible solute" alleviating the effects of water deficit by osmotic adjustment, act as osmoprotectants which stabilize membranes and proteins against osmotic alternations and participate in establish-

\footnotetext{
Abbreviations:

fagopyritol B1 - $O$ - $\alpha$-D-galactopyranosyl-( $1 \rightarrow 2)$-D-chiro-inositol; galactinol - $O$ - $\alpha$-D-galactopyranosyl-( $\rightarrow 1)$-L-myo-inositol; GPA - galactosyl pinitol A - $O$ - $\alpha$-D-galactopyranosyl-( $1 \rightarrow 2)-4-O$-methyl-D-chiro-inositol; D-pinitol - 3-O-methyl-D-chiro-inositol; RFOs - raffinose family oligosaccharides
}

ment of seed desiccation tolerance (Obendorf 1997). Some reports suggest that fructans revealing similar protective functions as RFOs (Hincha et al. 2002) can be involved in drought and cold stress tolerance of vegetative tissues (Cairns 2003).

In biosynthesis of both groups of oligosaccharides, sucrose plays a crucial function as a primary acceptor of monosaccharide residues (and in the case of fructans also as a fructosyl residue donor). Biosynthesis of RFOs includes transfer of galactose residue from galactinol to sucrose, forming raffinose, and following galactosyl transfer reactions leading to synthesis of stachyose and verbascose occur (Peterbauer and Richter 2001). This process is metabolically limited by sufficient amounts of myo-inositol and UDP-galactose - both substrates for synthesis of galactinol, which is an essential galactose donor for $\alpha-D-$ galactosides biosynthesis (Peterbauer and Richter 2001). Myo-inositol can be synthesized in the embryo (Chiera and Grabau 2007) or transported to the embryo from vegetative tissues (Gomes et al. 2004). Beside RFOs, seeds of some legumes also accumulate isomers or methylated ethers of myo-inositol, named cyclitols, and their $\alpha$-D-galactosides (Obendorf 1997; Peterbauer and Richter 2001). The most common cyclitols - D-chiro-inositol, D-pinitol (3-O-methyl-D-chiro-inositol) and D-ononitol (4- $O$-methyl-D-chiro-inositol) are accumulated in vegetative tissues of different plant species under osmotic stress conditions caused by salt stress, drought and cold. Cyclitols can act as osmoprotectants, cryoprotectants (Yancey 2005) and stabilize of prote- 
ins at high temperatures (Jaindl and Popp 2006). Therefore, they can be a target in genetic engineering of plants (Cherian et al. 2006). Only few results are available on the genetic transformation of myo-inositol $O$-methyltransferase (IMT1), which catalyzes methylation of myo-inositol in plants. For example, expression of a IMT1 cDNA from Mesembryantum crystallinum in tobacco resulted in the accumulation of methylated inositol (D-ononitol) and increased salt and drought tolerance (Sheveleva et al. 1997). Introduction of imt gene from $M$. crystallinum into soybean embryogenic cultures resulted in increased accumulation of D-ononitol and D-pinitol in somatic embryos. However, the level of D-pinitol in both expanding and mature leaf tissues of transgenic and non-transformed plants was similar (Chiera et al. 2006). It means that the efficiency of plants' transformation for D-pinitol production can be limited by epimerase, converting D-ononitol to D-pinitol. This enzyme has yet to be isolated and characterized. Chiera et al. (2006) suggested that myo-inositol may limit D-ononitol levels, ultimately limiting pinitol production.

Changes in the content of free cyclitols during seed development can be a key factor regulating accumulation of $\alpha$-D-galactosides in maturing seeds (Lahuta et al. 2005a). In seeds of various Vicia species, higher concentration of D-pinitol than that of myo-inositol throughout seed development and maturation coincides with accumulation of higher amounts of galactosyl pinitols and affects accumulation of RFOs. Feeding stem-pod-leaf explants of $V$. hirsuta and $V$. tetrasperma (Lahuta et al. 2005b, c) with D-pinitol (naturally occurring in both vetch species) and D-chiro-inositol (not detectable in vetches) increased accumulation of appropriate galactosyl cyclitols and decreased accumulation of verbascose. Similarly, soybean feeding experiments with cyclitols showed competition between cyclitols and sucrose as primary galactose acceptors in RFOs and galactosyl cyclitols biosynthetic pathway (Gomes et al. 2004; Obendorf et al. 2004). Therefore, it can be expected that the introduction of cyclitols into developing cereal grains, naturally accumulating only one cyclitol, i.e. myo-inositol, can change accumulation of other soluble carbohydrates, particularly RFOs and modify tolerance of grains and seedlings to abiotic stresses. On the other hand, D-pinitol and D-chiro-inositol indicate some health benefits - both cyclitols and their galactosides can be helpful compounds in treatment of type 2 diabetes (lowering glucose level in blood), polycystic ovary syndrome (Yoshida et al. 2006), and Alzheimer's disease (Nitz et al. 2008). Pinitol also possesses anti-inflammatory (Sethi et al. 2008) and anti-viral properties (Zhan et al. 2006) and has been implicated in the prevention of cardiovascular diseases (Choi et al. 2009). The latter suggests that D-pinitol can act as a potential anti-tumor agent (Sethi et al. 2008; Zhan and Lou 2007). Thus, it can be hypothesised that the presence of some cyclitols in cereal grains can improve health promoting properties.

In the present study, we have applied the previously described method for modification of composition of soluble carbohydrates in seeds without plant genetic modification by feeding explants with cyclitols (Lahuta et al. 2005b, c). The primary objective to this study was the evaluation of the effect of exogenously applied D-chiro-inositol and D-pinitol (both cyclitols not naturally present in cereals) on accumulation of soluble carbohydrates in maturing grains of wheat, triticale and barley.

\section{MATERIALS AND METHODS}

\section{Plant material}

Plants of winter cereals: wheat (Triticum aestivum cv Trend), and triticale (Triticosecale Witmmack cv. Wanad) were grown on experimental fields of the University of Warmia and Mazury in Olsztyn (north-east of Poland, longitude $54^{\circ} \mathrm{N}, 20.5^{\circ} \mathrm{O}$ ) in the growing season $2007 / 2008$. Spring barley (Hordeum vulgare L. cv Bies) was cultivated in the crop year 2008. Plants for explant feeding experiments were collected about 20-24 days after pollination (grain dry weight content $46-50 \%$, soft-hard dough maturation stage).

\section{Dry weight and viability assays}

Grains isolated from ears before and after explant feeding were dried at $90^{\circ} \mathrm{C}$ for 24 hours. The dry weight (DW) content was expressed as \% of fresh weight. The viability of maturing grains before and after explant feeding with free cyclitols was estimated by germination test according to ISTA (1999) standards. Grains were germinated on Petrie dishes containing wet germination paper (50 grains from 3-5 replicates in each) at $20^{\circ} \mathrm{C}$ in the dark for 6 days. Grains were scored as germinated when coleoptile or root pierced the pericarp and epidermis and reached 1-2 $\mathrm{mm}$ in length.

\section{Feeding stem-flag leaf-ear explants D-chiro-inositol and D-pinitol}

Explants containing the ear, flag leaf, peduncle, last node and $2 \mathrm{~cm}$ long part of internode were incubated in 2.5, 5.0 and $7.5 \mathrm{ml}$ of water (control) or water solutions of D-chiroinositol, D-pinitol (at $50 \mathrm{mM}$ concentration each) for 48 hours (for complete uptake of feeding solution). Then explants (5-10 from each treatment) were slow dried under laboratory conditions (temperature $20-24^{\circ} \mathrm{C}, \mathrm{RH} 30-40 \%$, natural light/dark period, July/August) for 30 days. Soluble carbohydrates were analyzed in whole grains. For comparison of the concentration of soluble carbohydrates in the embryo and endosperm tissues, dry triticale grains (from explants fed with $7.5 \mathrm{ml}$ of water or cyclitols solutions) were imbibed in sterile double distilled water for 3 hours and then separated into the embryo (plus scutellum) and endosperm (with pericarp and epidermis).

\section{Extraction and analysis of soluble carbohydrates}

The extraction and analysis of soluble carbohydrates by the high-resolution gas chromatography method were performed as described previously (Lahuta et al. 2006). Carbohydrates were quantified by using commercially available standards: glucose, fructose, sucrose, maltose, maltotriose, raffinose, stachyose, myo-inositol (Sigma), galactinol (Wako, Ireland), 1-kestose (Fluka, Germany), D-chiro-inositol and D-pinitol (Industrial Research Ltd., New Zealand). Other standards were extracted and purified from natural sources. Standard of galactosyl pinitol A was isolated and purified from seeds of Vicia villosa as was described earlier (Szczeciński et al. 2000), and standard of fagopyritol B1, isolated and purified from buckwheat seeds, was donated by M. Horbowicz (University of Podlasie, Siedlce, Poland). The content of carbohydrates was calculated from standard curves of an appropriate component. Xylitol (Sigma) was used as an internal standard. Results of analyses 
are means of three independent replicates \pm SE. Results were statistically analyzed by ANOVA and Tukey's post test $($ at $\mathrm{P}<0.05)$ in a GraphPadPrism 3.0 program (USA).

\section{RESULTS AND DISCUSSION}

Maturing cereal grains before the feeding experiment contained sucrose and 1-kestose, as main soluble carbohydrates (from $72 \%$ up to $92.5-94.5 \%$ of total soluble carbohydrates for barley, wheat and triticale, respectively, Fig. 1). The remaining soluble carbohydrates were: fructose, glucose, myo-inositol, galactinol (data not shown) and maltose. Their concentration was below $1 \mathrm{mg} \mathrm{g}^{-1}$ of dry weight (DW), except maltose in barley grains $\left(3.8 \mathrm{mg} \mathrm{g}^{-1} \mathrm{DW}\right.$, Fig. 1C). The total concentration of soluble carbohydrates reached 2.3-3.1\% DW (for wheat and triticale or barley, respectively). Feeding explants with water and then drying whole explants accelerated grain maturation and reduced the total concentration of soluble carbohydrates in grains by 25,50 and $60 \%$ (for wheat, triticale and barley, respectively). During maturation drying grains accumulated galactinol (Fig. 2) and raffinose (Fig. 1). Although the accumulation of raffinose (and its higher homologues) during natural drying of seeds is well documented (for review see Obendorf 1997), little is known about accumulation of 1-kestose in maturing cereal grains. 1-Kestose can be an initial oligomer from which biosynthesis of different linear or branched fructans with higher degree of polymerization starts (Valluru and Van den Ende 2008). In our study, during gas chromatographic separation of the fraction of soluble carbohydrates extracted from grains only 1-kestose was identified. Two peaks with retention times appropriate for oligosaccharides at DP3-4 were detected, but not identified. The concentration of both compounds (probably oligofructans) calculated according to the known nearest standard (1-kestose) was low ( $\left.<1 \mathrm{mg} \mathrm{g}^{-1} \mathrm{DW}\right)$ and decreased in grains dried in planta (data not shown).

Feeding explants with D-chiro-inositol or D-pinitol caused accumulation of both cyclitols in grains, as expected. Grains from explants fed with D-chiro-inositol synthesized also its mono-galactoside - fagopyritol B1 (Fig. 3). Grains accumulating D-pinitol contained also small amounts of a product of D-pinitol demetylation - D-chiro-inositol and traces of fagopyritol B1 (data not shown). In grains containing D-pinitol its mono-galactoside, i.e. galactosyl pinitol A (GPA) was present, but at a much lower level, than that of fagopyritol B1 in grains accumulating D-chiro-inositol (Fig. 3). The much more intense formation of fagopyritol B1 than GPA can be explained by the involvement of different enzymes in synthesis of both types of galactosyl cyclitols. Synthesis of fagopyritol B1 occurs via galactosylation of D-chiro-inositol by galactinol synthase (Gols) with UDP-galactose as the galactosyl donor (Obendorf et al. 2004). The presence of fagopyritol B1 and absence of fagopyritol A1 (which can be also synthesized by different isoforms of GolS, Ueda et al. 2005), suggests that in cereal grains one form of GolS occurs, similarly to vetch (Lahuta et al. 2005b, c) and soybean seeds (Gomes et al. 2004). Probably this was a reason of the lowering level of galactinol in wheat and triticale grains accumulating D-chiro-inositol (Fig. 2A, B). The much lower content of GPA than that of fagopyritol B1 can be a result of the low activity of
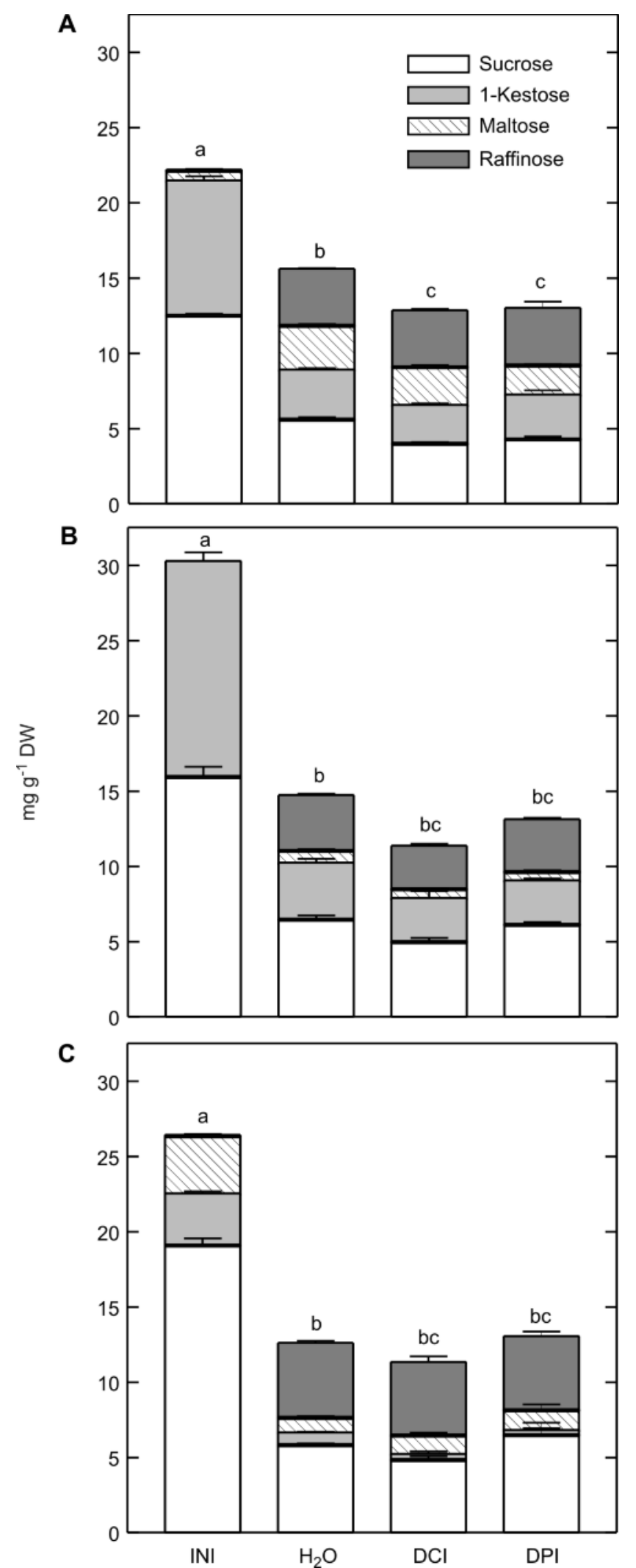

Fig. 1. The concentration of sucrose, maltose, raffinose and 1-kestose in grains of wheat (A), triticale (B) and barley (C) before (Initial, INI) and after stem-flag leaf-ear explant feeding with $7.5 \mathrm{ml}$ of $\mathrm{H}_{2} \mathrm{O}$, D-chiro-inositol (DCI) or D-pinitol (DPI) solution and followed slow drying of explants. Means \pm SE $(n=3)$. The same letters above the bars indicate not significant differences $(\mathrm{P}<0.05)$ after Tukey's correction for multiple comparisons.

stachyose synthase (STS), which is believed to be an enzyme responsible for synthesis of galactosyl pinitols (Peter- 
A
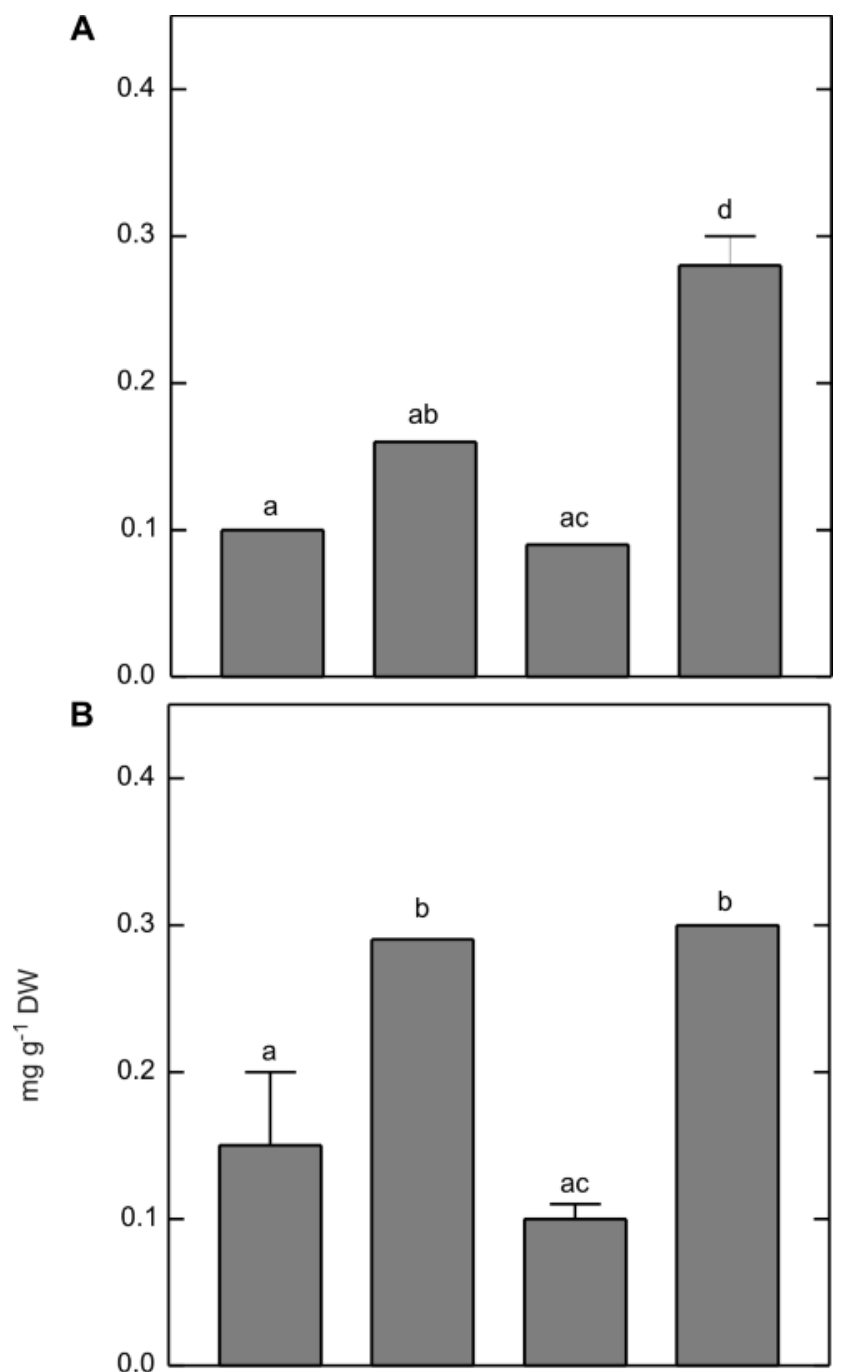

C

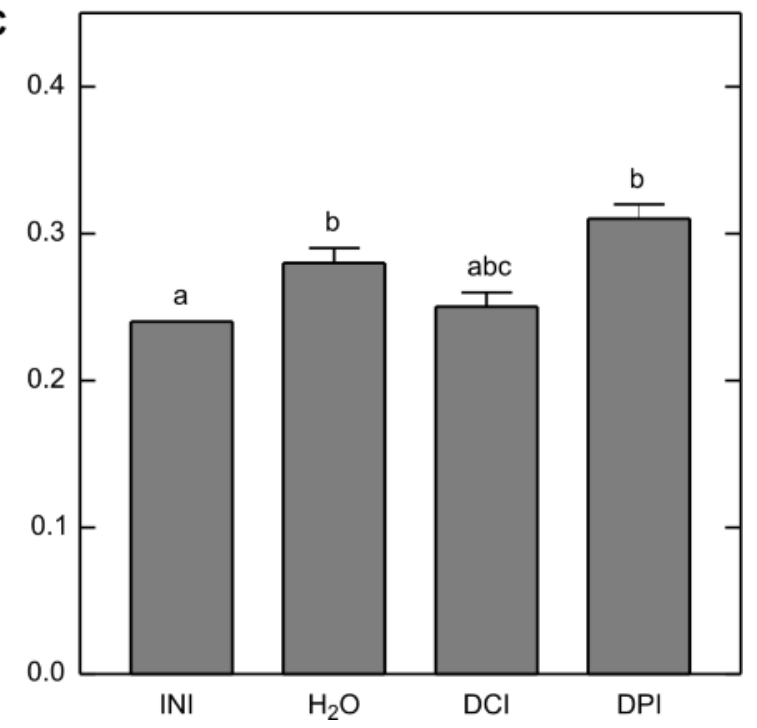

Fig. 2. The concentration of galactinol in grains of wheat (A), triticale (B) and barley (C) before (Initial, INI) and after stem-flag leaf-ear explant feeding with $7.5 \mathrm{ml}$ of $\mathrm{H}_{2} \mathrm{O}$, D-chiro-inositol (DCI) or D-pinitol (DPI) solution and followed slow drying of explants. Means \pm SE $(n=3)$. The same letters above the bars indicate not significant differences $(\mathrm{P}<0.05)$ after Tukey's correction for multiple comparisons.

bauer and Richter 2001). In maturing cereal grains stachyose was not detected and it can be hypothesized that raffino-
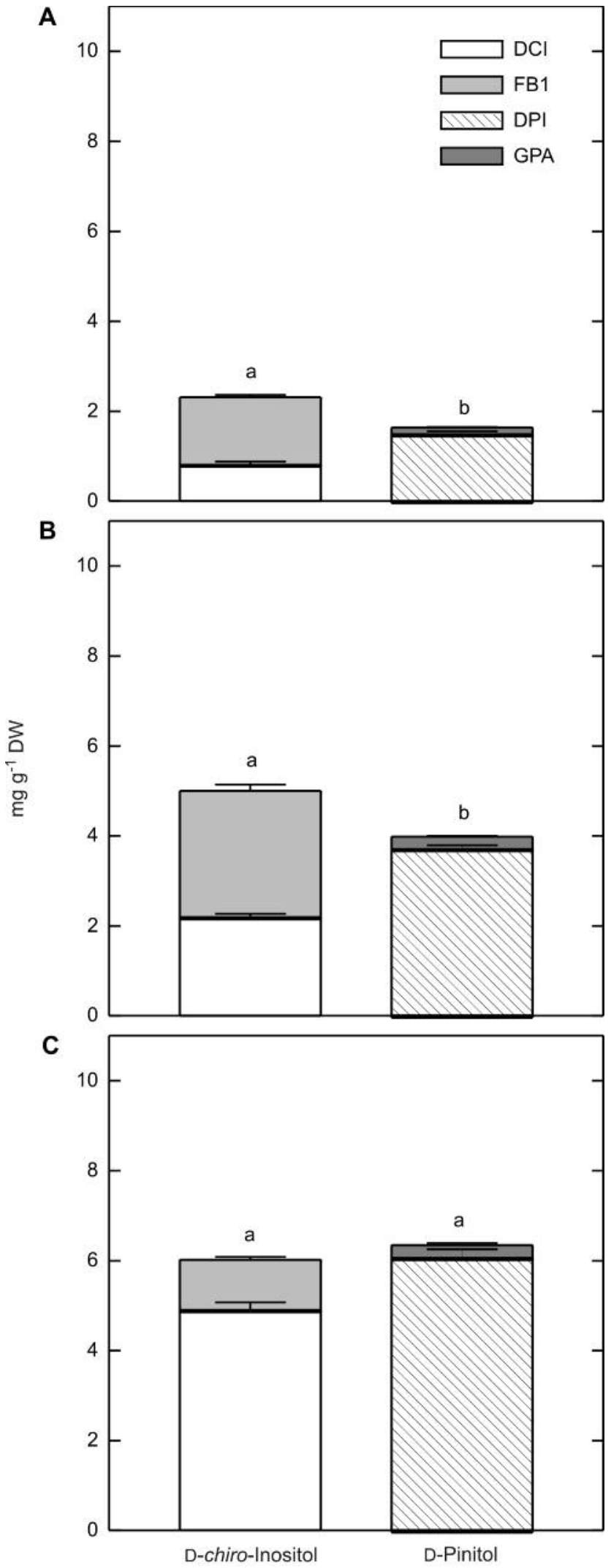

Feeding solution

Fig. 3. The concentration of D-chiro-inositol, D-pinitol and their appropriate $\alpha$-D-galactosides in grains of wheat (A), triticale (B) and barley (C) after stem-flag leaf-ear explant feeding with $7.5 \mathrm{ml}$ of D-chiro-inositol or D-pinitol solution and followed slow drying of explants. Means \pm SE $(\mathrm{n}=3)$. Abbreviations: DCI - D-chiro-inositol; FB1 - fagopyritol B1; DPI - D-pinitol, GPA - galactosyl pinitol A. The same letters above the bars indicate not significant differences $(\mathrm{P}<0.05)$ after Tukey's correction for multiple comparisons. 


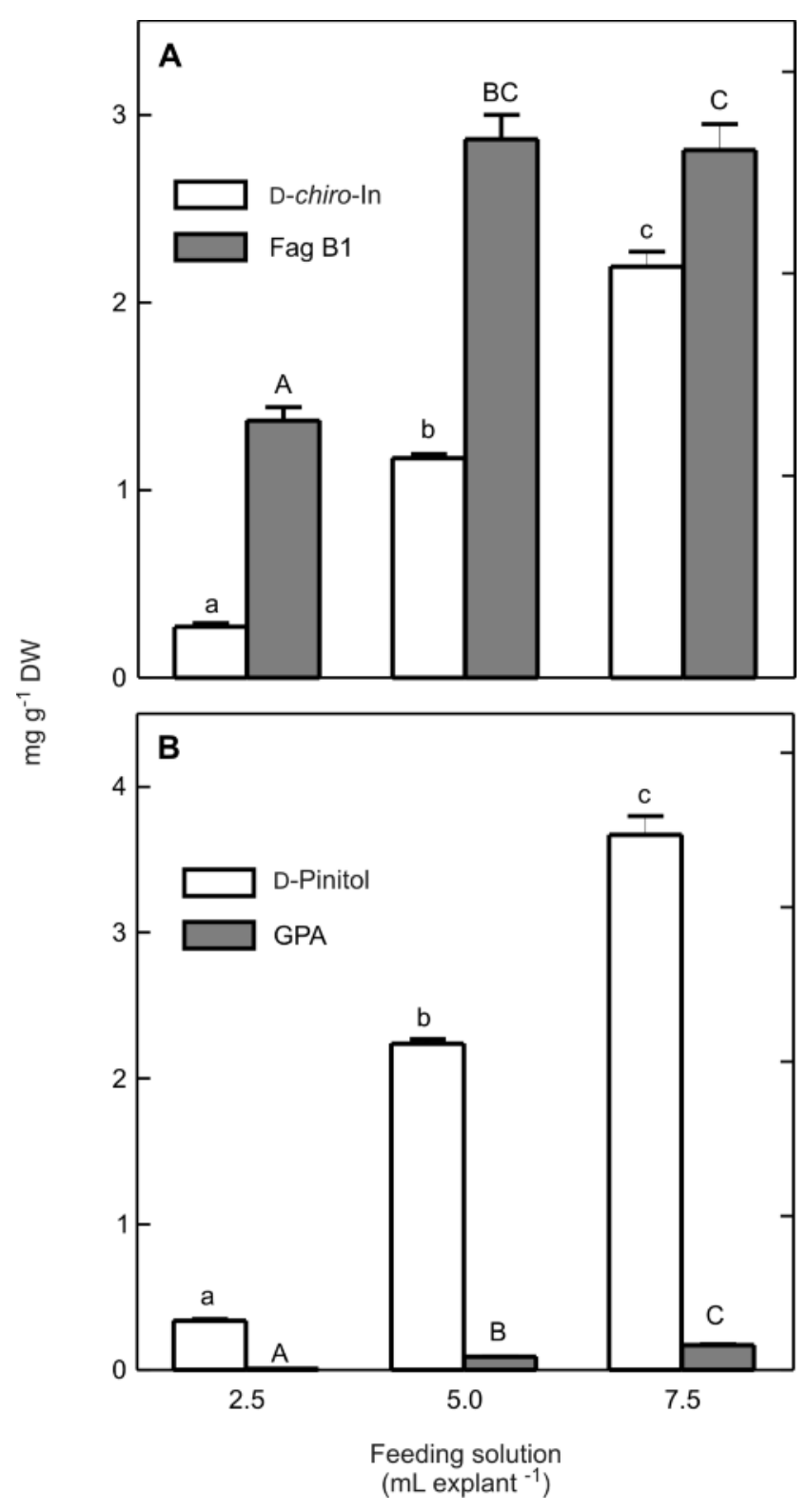

Fig. 4. The effect of volume of cyclitol solution (D-chiro-inositol - A, and D-pinitol - B, at $50 \mathrm{mM}$ concentration each) used for stem-flag leaf-ear explant feeding on the concentration of free cyclitols and appropriate galactosyl cyclitols in triticale (Triticosecale Wittmack cv Grenado) grains. Means \pm S E (n=3). Abbreviations: D-chiro-In - D-chiro-inositol; Fag B1 fagopyritol B1; GPA - galactosyl pinitol A. Bars with the same letters are not significantly different $(\mathrm{P}<0.05)$ after Tukey's correction for multiple comparisons.

se synthase (RS) rather than STS was engaged in synthesis of GPA. Raffinose synthase partially purified from pea seeds, beside synthesis of raffinose, can also catalyse transfer of galactose residues from galactinol to D-pinitol, producing GPA (Peterbauer et al. 2002). The low level of accumulated GPA can be a confirmation of low affinity of RS to D-pinitol as a galactosyl acceptor, as it was indicated in pea (Peterbauer et al. 2002).

Accumulation of cyclitols in cereal grains correlated with amounts of cyclitols used for explant feeding (Fig. 4). The correlation coefficient between amounts of cyclitols for explants feeding and cyclitols accumulated in grains reached level $r=0.99$. However, the efficiency of cyclitol uptake by grains, calculated as $\%$ of to the total amounts of cyclitols used for explant feeding, was relatively low. The efficiency of cyclitol uptake by grains of triticale (5.5 and $7.5 \%$ for D-pinitol and D-chiro-inositol, respectively) and barley (10.6 and 9.5\%) was a little higher and than that for wheat grains (3.2 and 3.5\%). Despite the low efficiency of cyclitols uptake, cyclitols and their galactosides constituted up to $10-14 \%$ (wheat), 22-29 (triticale) and 30\% (barley) of total soluble carbohydrates in grains. In the uptake of cyclitols by the embryo some factors can be involved, like type and concentration of cyclitols, duration of explant feeding, grain maturation stage, cyclitol transporters, etc. Until now, there have been no data available on the transporters facilitating uptake of D-chiro-inositol and D-pinitol by developing embryos. In vegetative tissues of Arabidopsis different forms of plasma membrane localized transporters of cyclitols have been found: AtINT4, transporting D-pinitol beside myo-inositol and AtINT2, transporting also D-chiro-inositol (Schneider et al. 2007). Our experiments indicated that maturing grains of barley accumulated more cyclitols than grains of triticale and wheat (Fig. 3). In grains of each cereal species the amount of D-chiro-inositol in free and bound form (as fagopyritol B1) equalled amounts of D-pinitol (free and bound as GPA) accumulated during explant feeding and drying. This means that common transporter involved in cyclitols transport into grains can operate in grains of investigated species.

In maturing seeds of vetch (Lahuta et al. 2005a, b) and soybean (Gomes et al. 2004; Obendorf et al. 2008) the accumulation of cyclitols disturbed accumulation of mainly raffinose oligosaccharide - verbascose (in vetch) or stachyose (in soybean), but no raffinose. Stachyose and verbascose were not detected before and after grains drying in wheat, triticale and barley grains. The uptake of cyclitols (and synthesis of their galactosides) did not affect accumulation of raffinose (Fig. 1).

Analyses of soluble carbohydrates in the embryo and endosperm of triticale grains after feeding experiment indicated that the concentration of sugars in the embryo was $c a$. 10 -fold higher than that in the endosperm tissues (Table 1), which is characteristic for cereals grains (Henry and Saini 1989). Similar differences in carbohydrate concentration were found between the embryonic axis and cotyledons in dicotyledonous seeds (Obendorf 1997). The presence of fagopyritol B1 or GPA at higher concentration in the triticale embryo than in the endosperm (in grains fed with D-chiro-inositol or D-pinitol, respectively) suggests that synthesis of these compounds and raffinose can occur in the same tissues and via a common biosynthetic pathway.

The germinability of wheat, triticale and barley grains (measured after explant feeding, drying and grains storage for 30 days under laboratory conditions in paper bags) reached $95-100 \%$ (data not shown), which means that accumulation of new cyclitols did not affect grains maturation.

\section{CONCLUSIONS}

In our study, we applied a simple and relatively fast method for modification of soluble carbohydrates in maturing cereal grains without plant genetic transformation. The results indicate possible translocation of D-pinitol or D-chiro-inositol into maturing cereal grains, and low ability of grains to use cyclitols as galactosyl residue acceptors. Accumulation of cyclitols mainly in the free form had no effect 
TABLE 1. The concentration of soluble carbohydrates in the embryo (A) and endosperm (B) of triticale grains matured on explants fed with 7.5 ml of water, D-chiro-inositol and D-pinitol. Means \pm SE $(n=3)$.

\begin{tabular}{|c|c|c|c|c|c|c|}
\hline \multirow{4}{*}{ Carbohydrate } & \multicolumn{6}{|c|}{ Feeding solution } \\
\hline & \multicolumn{2}{|c|}{$\mathrm{H}_{2} \mathrm{O}$} & \multicolumn{2}{|c|}{$50 \mathrm{mM}$ D-chiro-Inositol } & \multicolumn{2}{|c|}{50 mM D-Pinitol } \\
\hline & A & B & A & $\mathrm{B}$ & A & B \\
\hline & \multicolumn{6}{|c|}{$\mathrm{mg} \mathrm{g}^{-1}$ dry weight } \\
\hline Fructose & $0.47 \pm 0.07$ & $0.09 \pm 0.01$ & $0.25 \pm 0.02$ & $0.06 \pm 0.01$ & $0.15 \pm 0.00$ & $0.03 \pm 0.01$ \\
\hline Glucose & $0.53 \pm 0.00$ & $0.11 \pm 0.01$ & $0.33 \pm 0.05$ & $0.05 \pm 0.01$ & $0.75 \pm 0.07$ & $0.21 \pm 0.02$ \\
\hline Sucrose & $62.75 \pm 5.96$ & $2.15 \pm 0.24$ & $57.20 \pm 8.39$ & $2.14 \pm 0.12$ & $67.34 \pm 0.16$ & $2.53 \pm 0.28$ \\
\hline Maltose & $2.96 \pm 0.09$ & $1.74 \pm 0.30$ & 0.00 & $0.84 \pm 0.25$ & $2.42 \pm 0.03$ & $1.58 \pm 0.20$ \\
\hline Raffinose & $20.86 \pm 1.98$ & $0.95 \pm 0.08$ & $16.26 \pm 2.13$ & $0.80 \pm 0.14$ & $17.54 \pm 0.30$ & $1.02 \pm 0.46$ \\
\hline 1-Kestose & $41.96 \pm 3.94$ & $2.06 \pm 0.17$ & $32.82 \pm 4.21$ & $1.89 \pm 0.21$ & $35.29 \pm 2.59$ & $2.79 \pm 0.33$ \\
\hline Unk $1+2 *$ & $2.75 \pm 0.37$ & $0.77 \pm 0.07$ & $1.04 \pm 0.12$ & $0.91 \pm 0.15$ & $2.69 \pm 0.29$ & $1.57 \pm 0.21$ \\
\hline myo-Inositol & $2.07 \pm 0.10$ & $0.15 \pm 0.01$ & $1.64 \pm 0.13$ & $0.13 \pm 0.00$ & $1.56 \pm 0.01$ & $0.17 \pm 0.01$ \\
\hline Galactinol & $4.82 \pm 0.42$ & $0.05 \pm 0.00$ & $2.93 \pm 0.37$ & 0.00 & $6.13 \pm 0.02$ & $0.08 \pm 0.01$ \\
\hline D-chiro-In & 0.00 & 0.00 & $6.26 \pm 0.66$ & $1.75 \pm 0.22$ & $0.64 \pm 0.03$ & $0.06 \pm 0.00$ \\
\hline Fag B1 & 0.00 & 0.00 & $19.37 \pm 2.41$ & $2.05 \pm 0.47$ & $0.48 \pm 0.00$ & $0.06 \pm 0.01$ \\
\hline D-Pinitol & 0.00 & 0.00 & 0.00 & 0.00 & $11.68 \pm 0.14$ & $3.56 \pm 0.37$ \\
\hline GPA & 0.00 & 0.00 & 0.00 & 0.00 & $1.82 \pm 0.01$ & $0.32 \pm 0.02$ \\
\hline Total & $139.19 \pm 13.29$ & $8.07 \pm 0.83$ & $138.19 \pm 18.84$ & $10.62 \pm 1.23$ & $148.54 \pm 3.95$ & $14.00 \pm 1.86$ \\
\hline
\end{tabular}

* unknown compounds with retention time $\left(t_{\mathrm{R}}\right)$ between $\mathrm{t}_{\mathrm{R}}$ for 1-kestose and $\mathrm{t}_{\mathrm{R}}$ for stachyose, suggesting degree of polymerization DP3-4

on overall changes in composition of soluble carbohydrates during grain maturation. Although the ability to germination was not changed, deeper physiological studies on the possible role of cyclitols in grains are needed. Those results could be helpful for resolve the question if modification of cereals leading to accumulation of new cyclitols and their galactosides in grains can be a safe target for cereals genetic engineering.

\section{ACKNOWLEDGMENTS}

This work was supported by grant No N30312532/4015 obtained from Ministry of Scientific Research and Information Technology in Poland.

\section{LITERATURE CITED}

CAIRNS A.J. 2003. Fructan biosynthesis in transgenic plants. J. Exp. Bot. 54: 549-567.

CHIERA J.M., STREETER J.G., FINER J.J. 2006. Ononitol and pinitol production in transgenic soybean containing the inositol methyl transferase gene from Mesembryanthemum crystallinum. Plant Sci. 171: 647-654.

CHIERA J.M., GRABAU E.A. 2007. Localization of myo-inositol phosphate synthase (GmMIPS-1) during early stages of soybean seed development. J. Exp. Bot. 58: 2261-2268.

CHERIAN S., REDDY M.P., FERREIRA R.B. 2006. Transgenic plants with improved dehydration-stress tolerance, progress and future prospects. Biol. Plant. 50: 481-495.

CHOI M.S., LEE M.K., JUNG U.J., KIM H.J., DO G.M., PARK Y.B., JEON S.M. 2009. Metabolic response of soy pinitol on lipid-lowering, antioxidant and hepatoprotective action in hamsters fed-high fat and high cholesterol diet. Mol. Nut. Food Res. 53: 751-759.

GOMES C.I., OBENDORF R.L., HORBOWICZ M. 2004. myoInositol, D-chiro-inositol, and D-pinitol synthesis, transport, and galactoside formation in soybean explants. Crop Sci. 45: 1312-1319.
HENRY R.J., SAINI H.S. 1989. Characterization of cereal sugars and oligosaccharides. Cereal Chem. 66: 362-365.

HINCHA D.K., ZUTHER E., HELLWEGE E.M., HEYER A.G. 2002. Specific effects of fructo-and gluco-oligosaccharides in the preservation of liposomes during drying. Glycobiology 12: 103-110.

International Seed Testing Association 1999. International Rules for Seed Testing. Seed Sci. Technol. 27 (Suppl.)

JAINDL M., POPP M. 2006. Cyclitols protect glutamine synthetase and malate dehydrogenase against heat induced deactivation and thermal denaturation. Bioch. Biophys. Res. Commun. 345: 761-765.

LAHUTA L.B., GÓRECKI R.J., GOJŁO E., HORBOWICZ M. 2005a. Differences in accumulation of soluble $\alpha$-galactosides during seed maturation of several Vicia species. Acta Physiol. Plant. 27: 163-171.

LAHUTA L.B., HORBOWICZ M., GOJŁO E., GOSZCZYŃSKA J., GÓRECKI R.J. 2005b. Exogenously applied D-pinitol and D-chiro-inositol modifies the accumulation of $\alpha$-D-galactosides in developing tiny vetch (Vicia hirsuta (L.) S.F. Gray) seeds. Acta Soc. Bot. Pol. 74: 287-296.

LAHUTA L.B., GÓRECKI R.J., HORBOWICZ M. 2005c. High concentrations of D-pinitol or D-chiro-inositol inhibit the biosynthesis of raffinose family oligosaccharides in maturing smooth tare (Vicia tetrasperma (L.) Schreb.) seeds. Acta Physiol. Plant. 27: 505-513.

LAHUTA L.B. 2006. Biosynthesis of raffinose family oligosaccharides and galactosyl pinitols in developing and maturing seeds of winter vetch (Vicia villosa Roth.). Acta Soc. Bot. Pol. 75: 219-227.

NITZ M., FENILI D., DARABIE A.A., WU L., COUSINS J.E., MCLAURIN J. 2008. Modulation of amyloid-b aggregation and toxicity by inosose stereoisomers. The FEBS J. 275: 1663-1674 .

OBENDORF R.L. 1997. Oligosaccharides and galactosyl cyclitols in seed desiccation tolerance. Seed Sci. Res. 7: 63-74.

OBENDORF R.L., ODORCIC S., UEDA T., COSEO M.P., VASALLO E. 2004. Soybean galactinol synthase forms fagopyritol B1 but not galactopinitols, substrate feeding of isolated embryos and heterologous expression. Seed Sci. Res. 14: 321-333. 
OBENDORF R.L., SENSENIG E.M., WU J., OHASHI M., O’SULLIVAN T.E., KOSINA S.M., SCHNEBLY S.R. 2008. Soluble carbohydrates in mature soybean seed after feeding D-chiro-inositol, myo-inositol, or D-pinitol to stem-leaf-pod explants of lowraffinose, low-stachyose lines. Plant Sci. 175: 650-655.

PETERBAUER T., RICHTER A. 2001. Biochemistry and physiology of raffinose family oligosaccharides and galactosyl cyclitols in seeds. Seed Sci. Res. 11: 185-197.

PETERBAUER T., MACH L., MUCHA J., RICHTER A. 2002. Functional expression of cDNA encoding pea (Pisum sativum L.) raffinose synthase, partial purification of the enzyme from maturing seeds, and steady-state kinetic analysis of raffinose synthesis. Planta 215: 839-846.

SCHNEIDER S., SCHNEIDEREIT A., UDVARDI P., HAMMES U., GRAMANN M., DIETRICH P., SAUER N. 2007. Arabidopsis INOSITOL TRANSPORTER2 mediates $\mathrm{H}^{+}$symport of different inositol epimers and derivatives across the plasma membrane. Plant Phys. 145: 1395-1407.

SETHI G., AHN K.S., SUNG B., AGGARWAL B.B. 2008. Pinitol targets nuclear factor-kB activation pathway leading to inhibition of gene products associated with proliferation, apoptosis, invasion, and angiogenesis. Mol. Cancer Ther. 7: 1604$-1614$.

SHEVELEVA E., CHMARA W., BOHNERT H.J., JENSEN R.G. 1997. Increased salt and drought tolerance by D-ononitol production in transgenic Nicotiana tabacum L. Plant Phys. 115: 1211-1219.
SZCZECIŃSKI P., GRYFF-KELLER A., HORBOWICZ M., LAHUTA L.B. 2000. Galactosylpinitols isolated from vetch (Vicia villosa Roth.) seeds. J. Agric. Food Chem. 48: 2717-2720 .

UEDA T., COSEO M.P., HARRELL T.J., OBENDORF R.L. 2005. A multifunctional galactinol synthase catalyzes the synthesis of fagopyritol A1 and fagopyritol B1 in buckwheat seed. Plant Sci. 168: 681-690.

VALLURU R., VAN DEN ENDE W. 2008. Plant fructans in stress environments, emerging concepts and future prospects. J. Exp. Bot. 59: 2905-2916.

YANCEY P.H. 2005. Organic osmolytes as compatible, metabolic and counteracting crytoprotectants in high osmolarity and other stresses. J. Exp. Biol. 208: 2819-2830.

YOSHIDA K., YAMAGUCHI M., MORINAGA T., IKEUCHI M., KINEHARA M., ASHIDA H. 2006. Genetic modification on Bacillus subtilis for production of D-chiro-inositol, an investigational drug candidate for treatment of type 2 diabetes and polycystic ovary syndrome. App. Environ. Microbiol. 72: 1310-1315.

ZHAN T., LOU H. 2007. Synthesis of azole nucleoside analogues of D-pinitol as potential antitumor agents. Carbohydr. Res. 342: 865-869.

ZHAN T.-R., MA Y.-D., FAN P.-H., LOU H.-X. 2006. Synthesis of 4/5-deoxy-4/5-nucleobase derivatives of 3-O-methyl-D-chiro-inositol as potential antiviral agents. Chem. Biodiv. 3: 1126-1137. 